\title{
ARTIGO
}

Sociologias, Porto Alegre, ano 6, no 11, jan/jun 2004, p. 238-258

\section{Discursos cruzados: telenoticiários, HPEG e a construção da agenda eleitoral}

LUIS FELIPE MIGUEL*

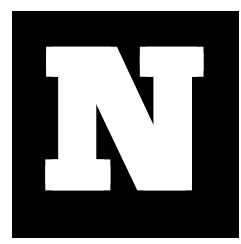

o modelo constitucional das democracias liberais, o voto é o momento crucial de expressão da soberania popular. ${ }^{1}$ Ao menos em tese, através da eleição, os cidadãos concedem sua autorização para que alguns de seus pares exerçam o poder político e, ao mesmo tempo, manifestam seu veredito sobre o desempenho passado de seus representantes, reelegendo-os ou substituindo-os - isto é, a eleição é a realização da accountability. Por isso, é reputado tão importante garantir a lisura do processo eleitoral, livrando-o de fatores que o desvirtuem.

Nos países de "democracia consolidada", na Europa Ocidental e na América do Norte, os mais ostensivos desses elementos são considerados sob controle: a intimidação física e a fraude na contagem dos votos (ainda que as eleições de 2000 na Flórida apresentem uma evidência contrária a tal afirmação). Mesmo em alguns países com democracias mais recentes e instituições menos sólidas, como o Brasil, o uso da força ou a falsificação dos resultados em geral são julgados problemas superados, que podem persistir aqui e ali, mas não a ponto de comprometer a legitimidade de eleições

* Professor do Depto. de Ciência Política da UnB e pesquisador do CNPq.

1 Uma versão inicial do artigo foi apresentada no XII Encontro Anual da Compós, realizado no Recife, de 3 a 6 de junho de 2003. Agradeço as generosas sugestões e críticas dos integrantes do GT Comunicação e Política, em especial de Antonio Albino Canelas Rubim, cuja leitura atenta contribuiu para limar muitos equívocos e lacunas, mas também de Mauro Porto, Wilson Gomes, Fernando Lattman-Weltman, Alessandra Aldé, Jorge Almeida e Afonso de Albuquerque. O texto se beneficiou também dos comentários de Regina Dalcastagnè e do parecerista anônimo de Sociologias. Por fim, agradeço a Sara Freire Simões de Andrade, aluna do curso de graduação em Ciência Política da UnB e bolsista do PIBIC/CNPq/UnB, que coletou os dados relativos à cobertura do Jornal Nacional e ao HPEG em 2002. Os erros que permanecem, é claro, são todos de minha responsabilidade. 
nacionais. As atenções se voltam, então, para dois outros fatores desvirtuantes, menos evidentes, mas não menos eficazes e, aliás, estreitamente ligados, que são o abuso do poder econômico e o controle da comunicação.

Dentro dessa discussão, o "Horário de Propaganda Eleitoral Gratuita" (HPEG) brasileiro, que distribui tempo de rádio e televisão entre quem disputa a eleição, pode ser encarado como um importante passo para a equalização das condições da disputa política. ${ }^{2}$ No jogo eleitoral brasileiro, ele se tornou um elemento central, altamente valorizado nos cálculos dos agentes políticos, quando projetam os lances seguintes de suas carreiras ou procuram alianças. Ele é, nas circunstâncias atuais da política brasileira, o grande mecanismo de valorização das hierarquias partidárias. Uma vez que o tempo é distribuído, em parte, de acordo com as bancadas no Legislativo, os partidos contam como blocos, como se agissem em uníssono. Ou seja, não importa que em 2002 parcelas importantíssimas do PMDB apoiassem Luiz Inácio Lula da Silva (PT) ou Ciro Gomes (PPS): uma vez que a convenção nacional determinou a coligação com o PSDB, todos os minutos do PMDB foram creditados à candidatura de José Serra. Pode-se dizer que, se não fosse por isso, a decisão da convenção seria quase que irrelevante, uma vez que não vincula as lideranças regionais nem coíbe dissidências cujo ônus, em condições de fraca identificação partidária, é baixo.

Do ponto de vista da democratização do processo eleitoral, são duas as vantagens mais relevantes do modelo brasileiro de acesso dos candidatos à televisão (e ao rádio):

a) o HPEG reduz a influência do dinheiro. Ele desvincula, ainda que parcialmente, o acesso à mídia da posse do poder econômico. Em outros países, como nos Estados Unidos, o espaço para que parti-

2 A rigor, a legislação brasileira prevê dois tipos de espaço para a política no rádio e na televisão: a propaganda partidária, destinada à difusão dos programas dos partidos políticos, veiculada fora do período de campanha, e a propaganda eleitoral, para a divulgação das candidaturas. Na prática, ocorre a antecipação das disputas eleitorais e o espaço de propaganda partidária acaba destinado à promoção de candidatos. Como os partidos ocupam esse espaço um a cada vez, ao longo de vários meses, a exposição na mídia garante ondas de crescimento nas pesquisas de intenção de voto. No primeiro semestre de 2002, de Roseana Sarney, a primeira, a Ciro Gomes, o último, todos os principais candidatos experimentaram um crescimento expressivo na "preferência" do eleitorado no momento em que estrelaram o espaço partidário na mídia. 
dos e candidatos se apresentem ao público precisa ser comprado, da mesma forma que a propaganda comercial. ${ }^{3}$ A desvinculação é apenas "parcial" porque o que o HPEG faz é proporcionar uma janela gratuita na mídia - gratuita para os partidos, já que o Estado ressarce as emissoras por meio de renúncia fiscal. No entanto, não garante os meios para produzir seus programas, o que resulta num profundo desequilíbrio na qualidade das mensagens, em benefício das campanhas mais ricas. Mesmo assim, não resta dúvida de que se trata de um avanço significativo;

b) o HPEG reduz a influência das empresas de comunicação de massa. Trata-se da principal medida no sentido de contrabalançar o poderio da mídia eletrônica na formação da opinião pública, garantindo um espaço na programação sob controle direto dos partidos. Isso permitiria a eles se libertarem dos constrangimentos impostos pelos veículos de comunicação. O HPEG livra a comunicação política da ditadura do sound bite de poucos segundos, dando a chance de serem apresentados discursos mais longos, complexos e aprofundados. E, em especial, permite que os partidos e candidatos proponham sua própria agenda temática e dêem visibilidade ao enquadramento da realidade que julgam mais apropriado.

Modelos semelhantes ao brasileiro são, por vezes, apresentados nos Estados Unidos como medida importante para o aprimoramento do processo eleitoral (Fishkin, 1991, p. 101). ${ }^{4}$ Entretanto, no Brasil, com o conhecimento adquirido após décadas de experiência com o HPEG - e muitas variações em sua fórmula - é possível avaliar com maior embasamento as suas potencialidades, mas também seus limites. O mais evidente deles, já referido, diz respeito à desigualdade nos recursos para a produção dos programas. Além disso, de acordo com uma crítica quase unânime, o predomí-

3 Na verdade, "quase" da mesma forma, já que existem cláusulas que visam gerar certa igualdade na propaganda política (as emissoras são obrigadas a aceitar material de todos os candidatos que as procurarem e a cobrar pela mesma tabela), inexistentes na propaganda comercial. A legislação eleitoral brasileira dos anos 1950 previa regras desse tipo (para o rádio).

4 Para uma comparação das regras de acesso dos candidatos ao rádio e à TV em diversas democracias eleitorais, ver Querino (2002). 
nio das técnicas de marketing político tem pasteurizado o conteúdo do horário eleitoral, comprometendo sua destinação inicial, que era gerar o debate político e esclarecer a cidadania.

Também existem problemas no cálculo de distribuição de tempo entre os diversos candidatos. Uma distribuição que tenda para a equanimidade iguala aventureiros que não representam nenhuma força política consistente a candidatos com peso social. Já a distribuição proporcional à votação obtida em eleições passadas, além de encontrar problemas para se efetivar, diante da volatilidade do quadro partidário brasileiro, cristaliza posições anteriores, em prejuízo do preceito democrático de permitir às minorias que se tornem maiorias.

No Brasil, para o primeiro turno das eleições, têm sido testadas fórmulas que mesclam os dois critérios (igualdade e proporcionalidade), mas, em geral, beneficiando os grandes candidatos (quando há segundo turno, a regra é a distribuição igual do tempo entre os dois concorrentes). Em 2002, por exemplo, os programas de José Serra, da aliança PSDB-PMDB, tinham 10 minutos e 23 segundos, contra 5 minutos e 19 segundos de Luiz Inácio Lula da Silva (PT-PL), 4 minutos e 17 segundos de Ciro Gomes (PPS-PDT-PTB), 2 minutos e 13 segundos de Anthony Garotinho (PSB) e 1 minuto e 23 segundos para cada um dos "nanicos" (José Maria, do PSTU, e Rui Pimenta, do PCO). ${ }^{5} \mathrm{O}$ tempo mais dilatado permitiu a Serra atacar seus adversários, o que era fundamental em sua estratégia de campanha, sem deixar de apresentar programas "propositivos", que lhe granjeavam ganhos simbólicos. ${ }^{6}$

Outro problema, em geral pouco lembrado, diz respeito à atuação da Justiça Eleitoral, que tem entre suas funções zelar pela correta utilização do HPEG, punindo candidatos que se excedam e concedendo "direitos de resposta" a adversários atingidos de forma considerada não aceitável. A cada eleição, surgem denúncias de favorecimento de determinados candi-

5 Além disso, os candidatos tinham direito a spots de 30 segundos, inseridos em meio à programação normal, também em número variável: 225 para Serra, 115 para Lula, 93 para Ciro, 49 para Garotinho e 31 para cada um dos "nanicos".

6 Tanto Serra quanto os outros candidatos buscaram reduzir o ônus da propaganda negativa, concentrando-a em spots com autoria pouco identificável ou no final dos programas do HPEG, quando a publicidade do candidato já havia sido ostensivamente encerrada (ver Figueiredo e Aldé, 2003: 7). 
datos, quer por parte do Tribunal Superior Eleitoral (TSE), quer dos tribunais estaduais. No entanto, independentemente da veracidade de tais acusações (que nunca são apuradas), a Justiça Eleitoral brasileira tende a engessar o debate político, por se atrelar a uma percepção normativa incorreta do que é uma campanha eleitoral e como ela deve desenrolar-se.

Não é uma percepção exclusiva do TSE ou de seus congêneres nos estados, e sim algo que está difundido pela sociedade e pelos "formadores de opinião". Ao que parece, numa "boa" campanha eleitoral, um candidato jamais deveria mencionar seus adversários. Deveria estar preocupado apenas em expor suas propostas, deixando ao eleitor a tarefa de determinar qual plataforma de governo é a melhor. O debate político, assim, toma basicamente a forma de um conjunto de monólogos; o confronto ocorre apenas na mente dos receptores das informações - ou, talvez, no jornalismo.

No entanto, a chamada "baixaria" da campanha eleitoral, muitas vezes, agrega informação relevante para orientar a decisão do voto, desconstruindo imagens produzidas pelo marketing, problematizando pontos das plataformas de governo alheias e trazendo o passado para a campanha - não o passado das "obras realizadas", mas o outro, das promessas não cumpridas, das alianças espúrias, das denúncias que mancham biografias. Enfim, ela ajuda a recompor a política enquanto espaço de conflito, algo que o discurso do marketing tende a negar, com sua ênfase nos atributos da unidade e da competência técnica.

Por fim, o problema mais sério: ainda que os candidatos se utilizem de uma via de comunicação direta com o público, o poder de agendamento da mídia permanece inconteste, dada sua aparente imparcialidade (e, portanto, sua legitimidade superior). Cabe observar que a relação entre os agentes do campo da mídia e do campo político é dinâmica e contraditória, marcada tanto por cooperação quanto por confronto (Miguel, 2002a). O diálogo - ou, em alguns momentos, sua ausência - entre o telejornalismo e o HPEG é revelador de alguns destes movimentos em que partidos, emis- 
soras e profissionais do vídeo buscam reforçar suas posições relativas. A reiteração da maior legitimidade do discurso da mídia é uma forma de garantir o controle sobre um importante recurso de poder.

Conforme busco demonstrar no restante deste texto, as quatro eleições presidenciais diretas brasileiras do período pós-autoritário revelam diferentes padrões de relacionamento entre HPEG e telejornalismo. Com exceção da primeira (1989), uma constante é a impermeabilidade dos noticiários de televisão às tentativas de agendamento temático feitas pela propaganda política. ${ }^{7}$

\section{Três eleições}

As eleições de 1989 são, ainda hoje, o principal exemplo da efetividade política do HPEG. Os dois candidatos que chegaram ao segundo turno Fernando Collor de Melo (PRN) e Lula - foram exatamente aqueles que apresentaram programas de televisão mais inovadores, revolucionando a linguagem da propaganda política no país. O desempenho do candidato do PT, em especial, costuma ser apresentado como a prova da importância do horário eleitoral (por exemplo, Lima, 1992, p. 133). Ele dobrou suas intenções de voto durante a exibição da campanha na TV, passando de 7\% aos $14 \%$ que garantiram sua vaga no turno final. ${ }^{8}$ Além de Collor e Lula, um terceiro candidato, o cardiologista Enéas Carneiro (Prona), destacou-se na televisão. Ele soube utilizar o exíguo tempo de que dispunha, folclorizandose e criando uma personagem que cresceria assustadoramente em eleições posteriores. Décimo-segundo colocado (entre 21 candidatos) em 1989, com

7 Embora, ao longo do texto, vá falar-se com frequêencia do "telejornalismo", os dados correspondem em geral ao Jornal Nacional, da Rede Globo de Televisão, que é, de longe, o principal telenoticiário do país, em número de espectadores. Dadas as condições de baixíssima pluralidade da mídia eletrônica brasileira, o comportamento de todas as emissoras costuma ser similar.

8 Cumpre observar que a inferência não é automática. O crescimento de Lula poderia ter ocorrido graças a fatores completamente estranhos ao HPEG (da mesma forma que a estabilidade nas intenções de voto não significa necessariamente que a propaganda gratuita é irrelevante). Em 1989, porém, o impacto dos programas eleitorais do PT era perceptível para qualquer observador. 
360 mil votos, tornou-se, nas eleições presidenciais seguintes, o terceiro (entre oito), com 4,6 milhões de votos.

Em 1989, o uso dos espaços de propaganda gratuita permitiu a partidos e candidatos um êxito razoável em suas tentativas de pautar a mídia eletrônica. Collor impôs a temática dos "marajás" (funcionários públicos com altos salários), graças, em grande medida, ao impacto de sua presença em vários programas partidários prévios à campanha eleitoral (ele ocupou tanto o espaço de sua agremiação quanto de seus aliados). É bem verdade que o candidato do PRN contava (ou passou a contar) com a simpatia dos controladores dos meios de comunicação, que foram seus parceiros na construção do enquadramento da realidade. Mesmo o PT, porém, foi capaz de introduzir alguns assuntos na pauta das emissoras. Em especial, os programas de Lula e também os de Collor - investiram em denúncias contra o governo federal; muitos dos casos de corrupção e desperdício apresentados no HPEG foram em seguida acompanhados pelos telejornais (e pela imprensa escrita).

Creio que um dos fatores que explicam tal receptividade dos telenoticiários à pauta da propaganda eleitoral é a ingenuidade ou despreparo das emissoras, ante a novidade da situação. A televisão brasileira nunca se havia defrontado com uma cobertura daquela magnitude. Surgida em 1950, a TV ainda engatinhava em 1960, ano das últimas eleições presidenciais antes da ditadura militar. Se, nos Estados Unidos, a disputa entre John Kennedy e Richard Nixon marcou o início da era da política televisual, no Brasil as campanhas de Jânio Quadros e do Marechal Lott ainda se fizeram ao velho estilo. O novo meio estava ausente muitos estados da Federação, o horário eleitoral ainda não existia (apareceu na legislação em 1962) e, muito menos, a idéia de um telenoticiário de abrangência nacional - o Jornal Nacional, da Rede Globo, inauguraria o formato em setembro de 1969.

Cumpre lembrar, ainda, que a eleição de 1989 foi "solteira", isto é, destinou-se exclusivamente a prover o cargo de presidente da República uma peculiaridade que a singulariza. A mudança na duração do mandato 
presidencial fez com que, de 1994 em diante, a disputa pela Presidência ocorresse junto aos governos estaduais, Assembléias Legislativas, Câmara Federal e Senado. A eleição solteira leva a um menor envolvimento do campo político e, portanto, amplia o potencial de intervenção dos meios de comunicação de massa. Em especial, diante da desmobilização de parte dos esquemas políticos tradicionais, avulta a importância da propaganda eleitoral como instrumento de sensibilização do público.

A receptividade à agenda do HPEG limitou-se a 1989. Nas eleições presidenciais posteriores, as emissoras se encontravam melhor preparadas para conter as influências sobre a pauta dos noticiários e impor sua própria primazia. Não se está querendo afirmar, aqui, que isso necessariamente evidencia alguma estratégia manipulativa em relação ao processo eleitoral. Conforme Daniel Hallin (1992) observou em seu artigo sobre a redução do tempo médio dos sound bites dos candidatos presidenciais na cobertura da televisão estadunidense, a ampliação do predomínio dos profissionais do jornalismo representa uma precaução contra as tentativas de instrumentalização do noticiário por parte dos políticos - no caso que ele estuda, através da edição da fala; aqui, pela blindagem da pauta.

Em 1994, a efetividade potencial da propaganda política na televisão foi limitada por restrições impostas pela legislação eleitoral (a lei 8.713, de 30 de setembro de 1993), que vetou a presença de convidados nos programas (só os candidatos podiam aparecer), bem como a exibição de cenas externas e a utilização de "trucagens" - um termo impreciso, uma vez que, a rigor, a própria edição já é uma trucagem, a trucagem básica da produção audiovisual. Conforme se observou já na época, reduzindo a capacidade de comunicação do HPEG, a lei 8.713 "serviu para, comparativamente, aumentar o poder dos media tradicionais quanto ao agendamento e ao enquadramento dos temas a serem discutidos na campanha e quanto à interpretação do andamento da disputa eleitoral" (Albuquerque, 1994, p. 186).

Uma análise muito difundida viu na mudança da legislação uma ma- 
nobra para atingir o candidato do PT, Lula, pois era conhecida a intenção de fazer de suas viagens pelo país - as "caravanas da cidadania" - um dos carros-chefe da propaganda na TV (Rubim, 1994, p. 59). De fato, parlamentares conservadores garantiram a aprovação da lei 8.713, com base nesse cálculo circunstancial. Mas cumpre ressaltar que a iniciativa legislativa partiu de deputados de esquerda, ligados ao ex-governador do Rio de Janeiro, Leonel Brizola, um notório adversário das transformações que a televisão introduziu no discurso eleitoral. Eles desejavam, por um lado, reduzir as desigualdades entre os candidatos e, por outro, obrigar ao aprofundamento do debate político. Os gastos com a produção diminuiriam, eliminando a utilização de recursos sofisticados, que os partidos e coligações mais pobres não podiam pagar. $\mathrm{E}$, sem externas, sem convidados e sem trucagens, não restaria aos candidatos outra alternativa que não a de sentar na frente da câmera e discorrer sobre o programa de governo.

No entanto, nenhum dos dois objetivos se cumpriu. As desigualdades de recursos se fizeram sentir com clareza. O programa do candidato governista Fernando Henrique Cardoso - filmado em película, contando com uma grande equipe de profissionais - apresentou uma qualidade técnica muito superior à de seus adversários. E o discurso extenso e aprofundado dos candidatos foi evitado, graças à utilização de brechas na lei, que permitiam o uso de jingles, de animações e mesmo de fotografias em rápida sucessão, simulando tomadas externas. Quase que sem exceção, os candidatos dos principais partidos buscaram reaproximar seus programas da linguagem da televisão "normal", com seus recursos visuais, seu discurso fragmentado, sua edição impaciente. Este é o habitat do telespectador/eleitor, que tende a rejeitar o que lhe causa estranhamento - e mantê-lo, portanto, era uma condição de efetividade das mensagens. Mas é também a linguagem à qual se acostumaram os políticos da nova geração e seus marqueteiros, que tinham dificuldade em mudar de registro.

Ainda assim, a lei 8.713 ocasionou uma relativa impotência diante da 
mídia. O HPEG mostrou-se incapaz de gerar fatos políticos. O fato dominante da campanha - a deflagração do Plano Real, de estabilização econômica - foi produzido pelo governo, com a cumplicidade dos meios de comunicação de massa, sem que enquadramentos desviantes pudessem ganhar plena visibilidade. Foram prejudicados os candidatos oposicionistas, que tiveram limitados seus recursos para reagir à campanha velada, travestida de objetividade jornalística, em favor de Fernando Henrique Cardoso.

O episódio das inconfidências do ministro da Fazenda, Rubens Ricupero, serve como o melhor exemplo. Não obstante seu impacto potencial intrínseco - as câmeras de televisão flagraram um ministro de Estado confessando ilícitos em conversa informal com um repórter - e o esforço dos partidos de oposição, o incidente obteve pequena repercussão eleitoral. As limitações ao HPEG impediram que o caso fosse explorado de forma a sensibilizar o público e, por outro lado, a grande mídia, Rede Globo de Televisão à frente, deram a ele pouco destaque e trataram de enterrá-lo com a maior brevidade possível.

Não é possível dizer que as restrições no formato do HPEG determinaram o resultado das eleições, isto é, que o vencedor seria outro, caso elas não existissem. Eram muitos os fatores que favoreciam a candidatura de Fernando Henrique Cardoso, e o impacto cotidiano do plano de estabilização econômica era sensível para a população, independentemente da forte campanha da mídia. Mas é inegável que enquadramentos desviantes tiveram dificuldades excepcionais para serem apresentados.

As eleições presidenciais seguintes, em 1998, vão mostrar que a legislação restritiva não foi a única responsável pela fraqueza do HPEG diante do poder de agendamento da mídia. Naquele ano, embora o período de veiculação da propaganda gratuita tenha sido reduzido de 60 para 45 dias, as regras voltaram a conceder ampla liberdade para a utilização dos recursos da linguagem televisiva, mantida apenas a vigilância da Justiça Eleitoral para coibir a veiculação de falsas acusações entre os candidatos. Ainda assim, os telejornais 
mantiveram-se pouquíssimo receptivos às temáticas abordadas no HPEG.

A própria disputa eleitoral de 1998 foi, em grande medida, exilada dos telenoticiários. O principal deles, o Jornal Nacional, da Rede Globo, dedicou nas 12 semanas que separaram o final da Copa do Mundo da data da votação - apenas uma hora e 15 minutos (ou 4,6\% do tempo total) às eleições. Ainda assim, quase todo esse tempo foi destinado à divulgação de pesquisas de intenção de voto, a reportagens de serviços (ensinando como operar a urna eletrônica) e ao fait-divers (eleições simuladas em tribos indígenas, por exemplo). A movimentação de campanha, declarações de candidatos, acordos políticos, tudo isso ficou com apenas 10 minutos (ou 0,6\% do tempo total do telejornal do período). O esvaziamento da cobertura eleitoral, do qual o Jornal Nacional foi o exemplo mais extremo, mas não o único, convergia com a estratégia do candidato à reeleição, Fernando Henrique Cardoso, que buscava desinflar o debate sucessório (Miguel, 2002b, p. 63-6).

A resistência à incorporação da agenda dos partidos no telenoticiário não se limitou ao item mais evidente: a própria disputa pela presidência. Temas exaustivamente apresentados pelos candidatos da oposição, sobretudo Lula, foram deixados de fora da agenda da mídia, como o recrudescimento da seca no Nordeste, com suas graves conseqüências sociais (menos de dois minutos no Jornal Nacional, no período citado), ou o aumento do desemprego no País (pouco mais de nove minutos).

O principal noticiário da Globo preferiu seguir sua própria agenda, que destacava problemas na comercialização de medicamentos no país (uma hora e 21 minutos), um serial killer em São Paulo (uma hora e 17 minutos) e o drama de um ator de telenovelas, baleado num assalto (44 minutos). Apenas um tema dominante da fase final da campanha, o agravamento da crise financeira internacional, esteve de fato presente no Jornal Nacional. Mas o enquadramento proposto pela oposição, que denunciava a política econômica governamental como responsável pela fragilidade da posição brasileira, foi olimpicamente ignorado (Miguel, 2002b, p. 72-84). 
Em 1998, portanto, ficou claro que mesmo sem as restrições legais ao uso dos recursos técnicos da comunicação televisiva, o HPEG não foi capaz de influir na composição da agenda da mídia. As eleições de 2002, numa conjuntura bastante diferente, revelaram que os principais agentes políticos compreenderam este fato - e adaptaram suas estratégias a ele.

\section{As eleições de 2002}

Se em 1998 ocorreu um pleito "invisível", dado o esvaziamento da cobertura na mídia, em 2002 a eleição recebeu extrema visibilidade. A Tabela 1 sumariza as transformações ocorridas no Jornal Nacional - que, mais uma vez, apenas apresenta uma versão extrema de um movimento perceptível em toda a mídia. De um tema menor, a eleição tornou-se o assunto dominante no noticiário. Enquanto a parca cobertura de 1998 privilegiava o fait-divers eleitoral e as sondagens de intenção de voto, o volumoso noticiário de 2002 concentrou-se no debate político propriamente dito. Praticamente emudecidos na eleição anterior, os candidatos ganharam voz em 2002, em séries de longas entrevistas em estúdios e na apresentação quase diária de suas declarações.

Eles não estiveram presentes apenas nos telejornais (e no HPEG). Antes do primeiro turno de 2002, as diferentes emissoras de televisão realizaram três debates entre os principais candidatos, tendo ocorrido mais um antes do segundo turno. ${ }^{9} \mathrm{Em} 1998$, a eleição foi decidida no primeiro turno, sem que as emissoras sequer aventassem a possibilidade de realizar algum debate na televisão.

No entanto, a grande presença das eleições no noticiário não significou sua abertura para o agendamento ou enquadramento temático proposto pelos partidos e candidatos no espaço da propaganda eleitoral gratuita. A

9 As emissoras desejavam realizar outros debates entre os dois candidatos que passaram para o segundo turno, mas o candidato Lula recusou seus convites, aceitando apenas o da Rede Globo. 
Tabela 1. Presença da disputa eleitoral no Jornal Nacional, em 1998 e 2002

\begin{tabular}{l|c|c}
\hline & 1998 & 2002 \\
\hline semanas sob análise $^{a}$ & 12 & 14 \\
\hline edições do Jornal Nacional no período & 72 & 84 \\
\hline edições com reportagens sobre as eleições & $26(36,1 \%)$ & $82(97,6 \%)$ \\
\hline tempo total do Jornal Nacional no período ${ }^{b}$ & $27: 53: 59$ & $43: 57: 14$ \\
\hline tempo sobre eleições presidenciais & $1: 16: 34(4,6 \%)$ & $12: 55: 50(29,4 \%)$ \\
\hline tempo sobre eleições estaduais e outros temas & $0: 23: 49(1,4 \%)$ & $2: 34: 59(5,9 \%)$ \\
\hline de política brasileira & $0: 10: 24(0,6 \%)$ & $8: 16: 51(18,8 \%)$ \\
\hline tempo de "debate eleitoral"c & $0: 07: 37(0,5 \%)$ & $2: 26: 50(5,6 \%)$ \\
\hline tempo total dos sound bites dos candidatos à & &
\end{tabular}

(a) Período entre o final da Copa do Mundo e a votação do primeiro turno.

(b) Excluídas as manchetes e as chamadas ao final de cada bloco.

(c) Reportagens sobre articulações políticas dos partidos e candidatos, eventos de campanha, entrevistas dos candidatos, propostas de governo etc.

Fonte: 0 autor.

Rede Globo construiu para si própria um papel de "regente" das eleições de 2002. Isso ficou transparente nas entrevistas em estúdio e, sobretudo, nos debates. O cumprimento das regras estritas determinadas pela produção e às quais os partidos tinham dado sua concordância era severamente garantido pelo mediador William Bonner (por vezes, secundado por Fátima Bernardes), em nome da manutenção de um "alto nível" do qual ele era o juiz - e que exilava boa parte da discussão política. Desejosos de evitar uma desavença com a emissora, os candidatos se submeteram às imposições.

Dentro do próprio Jornal Nacional, foi criado um espaço ostensivo de agendamento da campanha - séries de reportagens diárias sobre problemas brasileiros, veiculadas a partir de 5 de agosto. A cada semana, um novo tema era escolhido: distribuição de renda, desigualdades regionais, educação, emprego. As reportagens, que ao todo ocuparam 2 horas e 49 minutos do noticiário, eram precedidas pela vinheta "Eleições 2002" e, muitas vezes, terminavam com apelos para que o eleitor/telespectador descobrisse quais 
eram as propostas dos candidatos a respeito daquele problema. Ficava expressa, portanto, a idéia de que cabia ao jornalismo pautar os candidatos.

Em 2002 - e esta foi a novidade mais importante em relação às campanhas presidenciais anteriores - todos os principais candidatos optaram por deixar inquestionada a primazia da mídia na construção da agenda e também em seu enquadramento. Isto é, perceberam que aumentavam a efetividade potencial de seu discurso, caso aderissem às temáticas já dadas pelos veículos de comunicação. O movimento de adequação das esquerdas (e, sobretudo, da candidatura Lula) aos padrões dominantes do jogo político, com a ampliação do arco de alianças em direção ao flanco direito do espectro ideológico, completa profissionalização do marketing e pasteurização do discurso programático, foi também um movimento de capitulação na luta pela produção da agenda e dos enquadramentos da realidade (Miguel, 2003).

Vale a pena focar brevemente a evolução do principal agrupamento da esquerda brasileira, o Partido dos Trabalhadores que, nas quatro eleições, lançou Lula como candidato à presidência. Em 1989, o programa da Frente Brasil Popular (PT e aliados) adotou o formato da "Rede Povo", que, no nome, logotipo e vinhetas, parodiava a própria Globo. Com slogans do tipo "Aqui você vê a verdade na tevê", a Rede Povo, como anotou Albuquerque (1999, p. 170), indicava sua pretensão de ser uma alternativa à mídia comercial, implicitamente acusada de apresentar uma versão distorcida da realidade. Em 1994, o PT defrontou-se com o paredão do apoio unânime da grande mídia ao Plano Real e à candidatura de Fernando Henrique Cardoso; em 1998, outro paredão, o do silêncio que beneficiava a reeleição do presidente. Nas duas vezes, tentou, sem sucesso, modificar agenda e enquadramentos, denunciando as fragilidades do plano de estabilização monetária e o uso da máquina oficial em favor de um candidato; ou, então, indicando a seca no sertão nordestino e o crescimento dos índices de desemprego como problemas centrais a serem discutidos.

Já em 2002, a campanha de Lula preferiu uma postura subserviente 
em relação às temáticas e aos enquadramentos dominantes. A maior parte dos programas do PT foi ocupada com "propostas de governo", de acordo com a abordagem positiva/propositiva da disputa eleitoral, que é o modelo normativo dominante na mídia (e no senso comum). Os temas eram emprego e renda, educação, saúde e segurança, ou seja, os temas "clássicos" das campanhas eleitorais, abordados de forma praticamente idêntica pelos quatro principais candidatos. Dos 19 programas petistas do primeiro turno, 14 tiveram foco central em propostas relativas a esses quatro temas, e em apenas um caso, a concorrência para a compra de caças pela Força Aérea (programa de 7/9), tocou numa questão polêmica, ainda que com reduzida ressonância popular, da agenda pública. ${ }^{10}$

Em relação ao problema mais visível da conjuntura política e econômica, a rápida deterioração das finanças do país, Lula aderiu ao enquadramento hegemônico, que destacava a necessidade de gerar "confiança" nos operadores do mercado financeiro. Todos os principais candidatos à presidência foram levados a manifestar seu compromisso com a continuidade de alguns dos pilares do modelo econômico vigente - e mesmo a apoiar, em uníssono, o novo acordo com o Fundo Monetário Internacional, fechado no início de agosto. Um discurso em favor da "mudança", que era comum a todos os candidatos, até mesmo o governista José Serra (Almeida, 2003; Figueiredo e Aldé, 2003), combinava-se com a afirmação da manutenção das linhas gerais das políticas macroeconômicas.

Tratava-se de minorar a "incerteza" que as eleições provocavam no funcionamento da economia ou, dito de outra forma, de procurar restringir brutalmente a margem de manobra do novo governo em relação à política econômica. Nas entrevistas e nos debates, o âncora do Jornal Nacional, William Bonner, cobrava de todos (mas em especial dos três oposicionistas) compromissos com a "manutenção dos contratos", que se traduzia sobre-

10 Os outros quatro programas do primeiro turno tiveram como foco central: a apresentação de apoios de intelectuais, de obras de administrações petistas e, por duas vezes, apelo ao voto dos indecisos. No segundo turno, de 11 programas, seis dedicaramse aos temas listados. Os programas analisados foram os exibidos à noite. 
tudo no pagamento das dívidas externa e interna, e com o ajuste fiscal. Da forma como o diálogo era posto (e uma vez que nenhum candidato se dispunha a contestá-lo), parecia que o jornalista exigia algo tão evidente e consensual quanto a honestidade no trato com o dinheiro público - quer dizer, algo que não permitisse discordâncias no campo da política, algo que marcasse o desviante como portador de um déficit moral.

No entanto, o tema esteve ausente, quase que por completo, do HPEG. Falava-se de crise econômica e da necessidade de retomar o desenvolvimento, mas nem o PT nem seus adversários ousaram ocupar o espaço de propaganda gratuita para discutir as dívidas externa e interna, a relação do Brasil com o mercado financeiro mundial ou os acordos com o Fundo Monetário Internacional. Aparentemente, ou se sentiam satisfeitos com o enquadramento dominante na mídia, ou não consideravam vantajoso se contrapor a ele.

Apenas os candidatos da extrema-esquerda - José Maria (PSTU) e Rui Costa Pimenta (PCO) - investiram numa agenda alternativa, com enquadramentos desviantes. Nela, ganhavam destaque o acordo para a formação da Área de Livre-Comércio das Américas, um assunto ausente do telenoticiário e da campanha dos maiores partidos, e a relação entre o FMI e o Brasil, denunciada como imperialista. ${ }^{11}$ Com tempo exíguo, produção amadora e minúscula base social, não obtiveram maior repercussão junto à mídia, que ignorou (ou quase) seus esforços junto aos outros candidatos, que não consideraram necessário participar da discussão e, a julgar pelo resultado da votação, também junto ao eleitorado.

Isso não quer dizer que o HPEG tenha sido irrelevante na campanha eleitoral de 2002. Os dois candidatos que passaram ao segundo turno foram os que melhor aproveitaram o espaço de propaganda gratuita. ${ }^{12}$ Lula ampliou sua liderança ao longo da campanha na TV, que cumpriu um papel

11 Lula nem sequer citou a ALCA, ao longo de toda a campanha. O FMI apareceu duas únicas vezes, no segundo turno, na mesma fala (apresentada em 20/10 e reprisada 22/10), quando o candidato assinala sua posição "sensata" ao endossar os acordos. $12 \mathrm{~A}$ afirmação parece tautológica, uma vez que a principal evidência do bom aproveitamento do HPEG é o próprio êxito eleitoral. Mas cabe observar que Serra ganhou posições e Lula ampliou sua vantagem ao longo da exibição da propaganda na TV e no rádio. Os problemas de Anthony Garotinho e, sobretudo, de Ciro Gomes com suas equipes de produção foram amplamente noticiados na época. 
significativo na exitosa estratégia de remodelamento de sua imagem pública, tornando-o mais palatável para as elites econômicas e para o eleitorado conservador. Como observou Rubim (2003), ocorreram dois movimentos principais. O líder sindical "raivoso" foi substituído pelo conciliador (o "Lulinha paz e amor", na expressão do próprio candidato). E construiu-se a figura do grande negociador, ao mesmo tempo em que a capacidade de negociação foi erigida em atributo principal para o exercício da presidência - em substituição à experiência administrativa, calcanhar-de-aquiles do candidato do PT.

José Serra, por sua vez, venceu a acirrada disputa pela segunda vaga no segundo turno graças, em grande medida, ao uso dos programas eleitorais. Eles foram fundamentais para que o candidato do PSDB "desconstruísse" como diziam os marqueteiros - a candidatura de Ciro Gomes, que desceu do segundo para o quarto lugar nas pesquisas de intenção de voto. E, assim que Serra ocupou a segunda posição nas sondagens, seus programas passaram a apresentar uma pretensa enquete ("Lula ou Serra?"), numa estratégia ousada para consolidar uma polarização que estava longe de se ter constituído.

Mas é preciso ressaltar apenas que, da parte dos principais candidatos, foram raras e tênues as tentativas de influenciar, por meio do HPEG, a agenda do jornalismo. A propaganda eleitoral concentrou-se mais em embates ligados à imagem pública dos candidatos e muito menos na reinterpretação da realidade social.

\section{Conclusões}

A relativa incapacidade do HPEG em alterar a agenda da mídia não significa necessariamente sua irrelevância na construção da agenda pública. Afinal, agenda pública e agenda da mídia não se confundem. O que a pesquisa sobre mídia e política tem procurado demonstrar nos últimos 30 anos - desde a formulação da hipótese do agenda-setting no artigo inaugu- 
ral de McCombs e Shaw (1972) - é "apenas" a preponderância da segunda no estabelecimento da primeira. E o HPEG é valorizado exatamente por ser um instrumento que permitiria aos atores políticos uma comunicação com o público - e, portanto, uma influência sobre a agenda pública - sem a intermediação das empresas de radiodifusão e imprensa.

No entanto, o fracasso em sensibilizar a mídia - ou a posição subserviente em relação a ela - é um indício importante de que o HPEG não está conseguindo cumprir satisfatoriamente sua missão. Aos olhos do público, há uma importante diferença de legitimidade entre a propaganda política e o telenoticiário. Este está revestido pelos valores da imparcialidade, da neutralidade e da objetividade, que seriam próprios do jornalismo. Aquela não pode negar seu caráter de discurso interessado. No dia-a-dia das democracias eleitorais, o jornalismo coloca a si próprio na posição de juiz da veracidade e da correção dos discursos e das práticas políticas. No período excepcional da campanha às eleições, tal traço não se dilui. Ao contrário, é acentuado. Assim, quando um tema (ou um enquadramento) formulado no HPEG penetra no espaço da reportagem jornalística, ele ganha uma credibilidade que a disputa política, por si só, não é capaz de lhe dar. Além disso, as poucas semanas de veiculação da propaganda eleitoral - que, como visto, a partir de 1998, foi reduzida de 60 para 45 dias - dificilmente são capazes de reverter enquadramentos hegemônicos da realidade, muitas vezes sedimentados ao longo de anos.

Os indícios expostos acima sinalizam uma transformação no comportamento do telejornalismo, entre as eleições de 1989 e 2002, de uma maior permeabilidade às tentativas de agendamento partidas do HPEG para um maior fechamento, isto é, para um controle mais estrito dos profissionais da mídia sobre a construção da pauta dos noticiários. O campo da mídia não se dispõe facilmente a abrir mão de um recurso que lhe concede poder em face do campo político. O reconhecimento desse fato - e da impossibilidade aparente de modificá-lo, comprovada pelas experiências 
de 1994 e 1998 - levou os partidos à acomodação com a agenda temática da mídia, preferindo "remar a favor da corrente", em vez de tentar introduzir novos assuntos na discussão pública.

Trata-se de uma mudança que é congruente com movimentos próprios da política partidária de massa. Na medida em que a conquista da maioria dos votos é o objetivo crucial, há um incentivo ao aplainamento das arestas ideológicas, com a adoção de um discurso mais abrangente e mais difuso. Em síntese, o partido ideológico cede lugar ao partido catch-all. A profissionalização da disputa, por outro lado, faz das sondagens de "opinião pública" uma ferramenta indispensável para a construção do discurso dos candidatos - que se adapta àquilo que os eleitores esperam ouvir. Há, aí, uma nova via de adaptação à agenda midiática, já que a "opinião pública" superficial, colhida pelas sondagens, é fortemente dependente dos conteúdos da comunicação de massa.

A compreensão dos limites do HPEG não implica descartá-lo como desnecessário. Apesar de todas as suas imperfeições - e de ser incapaz de dar à democracia brasileira tudo o que se esperava dele -, trata-se de um (raro) instrumento voltado à geração de condições mais equânimes na disputa eleitoral. Diante dos problemas que o HPEG não resolve, porém, impõe-se a necessidade de buscar novas medidas que, no campo da política, contrabalancem os poderes do dinheiro e da mídia.

\section{Referências}

ALBUQUERQUE, Afonso de. Sem montagens e sem trucagens: a nova legislação eleitoral. Comunicação \& política, Rio de Janeiro, nova série, vol. I, no - 2. p. 184-6. 1994.

ALBUQUERQUE, Afonso de. Aqui você vê a verdade na tevê: a propaganda política na televisão. Niterói: MCII-UFF. 1999.

ALMEIDA, Jorge. Lula, Serra e a disputa pelo discurso da "mudança" em 2002. 
Trabalho apresentado no $12^{\circ}$ Encontro Anual da Compós, Recife, 3 a 6 de junho de 2003.

FIGUEIREDO, Marcus; ALDE, Alessandra. Intenção de voto e propaganda política: efeitos e gramáticas da propaganda eleitoral. Trabalho apresentado no $12 \mathrm{o}$ Encontro Anual da Compós, Recife, 3 a 6 de junho de 2003.

FISHKIN, James S. Democracy and deliberation: new directions for democratic reform. New Haven: Yale University Press. 1991.

HALLIN, Daniel C. Sound bite news: television coverage of elections, 1968-1988. Journal of Communication, Austin, vol. 42, no 2., p. 5-24. 1992.

LIMA, Venício A. de. Medios de comunicación y democracia: la construcción de un presidente brasileño. Telos, Madrid, no 29., p. 121-34. 1992.

MCCOMBS, Malcolm; SHAW, Donald. The agenda-setting function of mass media. Public Opinion Quaterly, New York, vol. 36, no 2, pp. 176-87. 1972.

MIGUEL, Luis Felipe. Os meios de comunicação e a prática política. Lua Nova, São Paulo, no 55-6, p. 155-84. 2002a.

MIGUEL, Luis Felipe. Política e mídia no Brasil: episódios da história recente. Brasília: Plano. 2002b.

MIGUEL, Luis Felipe. A eleição visível: a Rede Globo descobre a política em 2003. Dados, Rio de Janeiro, no 46, no prelo. 2003.

RUBIM, Antonio Albino Canelas. Política, media e eleições: 1989 e 1994. Comunicação\&política, Rio de Janeiro, nova série, vol. I, no 1, p. 53-62. 1994.

RUBIM, Antonio Albino Canelas. Cultura e política na eleição de 2002: as estratégias de Lula presidente. Trabalho apresentado no $12^{\circ}$ Encontro Anual da Compós, Recife, 3 a 6 de junho de 2003.

QUERINO, Ana Carolina. Legislação de radiodifusão e democracia: uma perspectiva comparada. Comunicação\&política, Rio de Janeiro, nova série, vol. IX, no 2, p. 152-89. 2002.

Recebido: $13 / 06 / 2003$

Aceite final: 16/12/2003 
Sociologias, Porto Alegre, ano 6, no 11, jan/jun 2004, p. 238-258

\section{Resumo}

O Horário de Propaganda Eleitoral Gratuita (HPEG) faculta aos candidatos um espaço de comunicação autônomo, em que suas mensagens não têm que passar pelo crivo dos grupos de mídia. O paper discute a eficácia do HPEG, em contraposição ao telejornalismo, e analisa a evolução da relação entre os dois nas quatro eleições presidenciais brasileiras do período pós-autoritário. Em 1989, os telenoticiários mostravam-se receptivos à agenda proposta pelos partidos em seus programas de TV, mas há um nítido fechamento nas eleições seguintes. Em 2002, os principais candidatos preferiram aderir à agenda e aos enquadramentos dominantes, reconhecendo a incapacidade do HPEG para alterar a pauta da mídia.

Palavras-chave: mídia e política, eleições, discurso político, agenda pública, televisão. 